\title{
Political Uncertainty, Public Expenditure and Growth
}

\author{
Julia Darby \\ Chol-Won Li \\ and \\ V. Anton Muscatelli \\ University of Glasgow
}

Correspondence to:
Julia Darby,
Dept. of Economics,
Adam Smith Building,
University of Glasgow,
Glasgow G12 8RT,
United Kingdom.
Tel: +44 1413304692
Fax: +44 1413304940
Email: J. Darby@ socsci.gla.ac.uk 


\section{Introduction}

There are a number of channels through which political instability can affect economic growth. One obvious channel is the impact which greater social unrest and political upheaval and revolution can have on the incentives to invest. It is quite apparent that the lack of protection for property rights may harm the prospects for private investment ${ }^{1}$, and may reduce foreign direct investment in a country ${ }^{2}$. Similarly, in countries where rulers are weak and run the danger of being overthrown, they might have an incentive to allow key groups to engage in rent-seeking activities, which may again harm economic growth ${ }^{3}$. There seems to be considerable empirical evidence that major political upheaval (as opposed to routine changes of governments following elections) and coups d'etat can adversely affect economic growth (see Alesina et al., 1996, Barro, 1996, and Easterly and Rebelo, 1993).

In modern democracies, where government changes are generally peaceful and follow constitutional norms, political instability may still have an impact on economic growth. The main mechanism at work in these models is through the impact of political instability on government myopia: forward-looking governments which have uncertain prospects of re-election may not be interested in carrying out long-term economic policies ${ }^{4}$. For instance, Svensson (1993) emphasises how governments may be less inclined to make improvements to the legal system. Calvo and Drazen (1997) show how policy uncertainty can distort the future path of investment decisions. In Devereux and Wen (1996) political instability encourages governments to run down the

\footnotetext{
${ }^{1}$ For theoretical models in which the lack of enforcement of property rights affects growth, see Tornell and Velasco (1992) and Benhabib and Rustichini (1996). For a survey, see Persson and Tabellini (1998).

${ }^{2}$ See Rodrik (1991).

${ }^{3}$ See Murphy et al. (1991).
} 
economy's asset base, thus encouraging future governments to increase capital taxation with the result that private investment, expecting higher future taxation, is reduced. Persson and Tabellini (1998) build a 2-period model in which capital taxation is used to finance public investment, which drives economic growth and enhances the future tax base. The problem is that public investment is less valuable for an incumbent government if re-election is uncertain, because less of the economy's future tax revenues will be spent on the incumbent's preferred public goods. Hence political instability (a greater uncertainty of re-election for the incumbent) reduces public investment because it increases policy myopia.

Empirically, there seems to be evidence in favour of a negative link between minor political instability (the frequency of changes in a government's political complexion) and economic growth (see Alesina et al., 1996, Perotti, 1996).

In this paper, we focus on the link between the political instability (due to uncertainty in electoral outcomes) and economic growth through the impact on a government's decisions on how to allocate government expenditure between public consumption and public investment. The value added of our contribution is the following. First, unlike some existing two-period models of the impact of political uncertainty on growth (see Persson and Tabellini, 1998) we propose an infinite horizon model where a particular equilibrium is generated by the dynamic interaction of an endogenous growth model with political dynamics. In two-period models government myopia generally arises because incumbent governments face a probability of not having access to the future benefits from current taxation and spending decisions for their political constituency. In our model, government myopia arises because of office

\footnotetext{
${ }^{4}$ The notion of policy myopia is quite common in political economy models. For alternative models of fiscal policy in which the incumbent has an incentive not to act in the social interest see Alesina and Tabellini (1990) and Milesi-Ferretti and Spolaore (1994).
} 
motivation, so that an incumbent government will perceive a more limited political benefit from decisions taken now which only impact with a lag on consumer utility. Thus political uncertainty leads to a shift of government budgets from capital spending to government consumption.

Second, unlike other attempts to model political uncertainty, we provide a full account of the preferences of consumers and how these affect the political equilibrium. The advantage of this is that we are able to compare the stochastic steady-state growth equilibrium under political uncertainty with that which would prevail in the presence of an optimal social planner. This allows us to consider the welfare implications of political uncertainty for the median voter.

Third, our focus is not only on the impact of the political environment for taxation decisions, but also on the allocation of government spending between government investment and consumption. Thus, our focus is rather different from that in other contributions to this area which tend to concentrate on inequality ${ }^{5}$, the enforcement of property rights, and public expenditures on different types of public goods. As explained below, we believe that the focus on the relationship between public investment and consumption is an important one, especially in the OECD economies.

The rest of this paper is structured as follows. In Section 2 we motivate our focus on the relationship between public investment and consumption. In Section 3 we outline our theoretical model and the main results. Section 4 concludes.

\footnotetext{
${ }^{5}$ See for example Saint Paul and Verdier (1993), Perotti (1993).
} 


\section{The Relationship Between Government Investment and Growth}

There is strong empirical evidence that government spending can have a significant impact on productivity growth both from production function estimates (see inter alia Aschauer, 1989, Munnell, 1990, Morrison and Schwartz, 1992) ${ }^{6}$. Work on cross-country panel studies show some evidence in favour of the hypothesis that spending on public infrastructure such as transport and communications enhances growth prospects (see Easterly and Rebelo, 1993), whilst the evidence on public educational spending tends to be more mixed (see Barro, 1996). In contrast, most studies tend to find a negative impact of government consumption on economic growth (see Barro, 1996) ${ }^{7}$.

One striking piece of casual empirical evidence from the post World War II war era is the rise in the proportion of current expenditures in total government spending in many of the OECD economies. Chart 1 shows how the proportion of government investment in total government spending has evolved in a number of OECD countries since $1960^{8}$. In particular the increase in government consumption and transfers has been widespread amongst OECD economies since the mid-1960s (see Alesina and Perotti, 1996). The other notable feature of government budgets in the OECD economies is that many of the attempts to stabilise increasing debt burdens in the late 1980s and 1990s have resulted in increases in taxation and in cuts in capital outlays. There are of course exceptions to this (especially the fiscal adjustment in Ireland in

\footnotetext{
${ }^{6}$ Although the size of the total impact of public capital spending on productivity growth is a matter of some debate (see Holtz-Eakin and Schwartz, 1994) and obviously varies between countries and sectors. ${ }^{7}$ For some contrary evidence from developing countries where sometimes capital spending is misallocated, see Devarajan et al. (1996).

${ }^{8}$ The countries considered are Australia (AU), Austria (AT), Belgium (BE), Canada (CA), Finland (FI), France (FR), Germany (GE), Ireland (IR), Italy (IT), Japan (JP), Netherlands (NL), Norway (NO), Sweden (SW), Switzerland (SZ) and the United Kingdom (UK). We have excluded small countries like Luxembourg, Israel and Iceland from our analysis.
} 

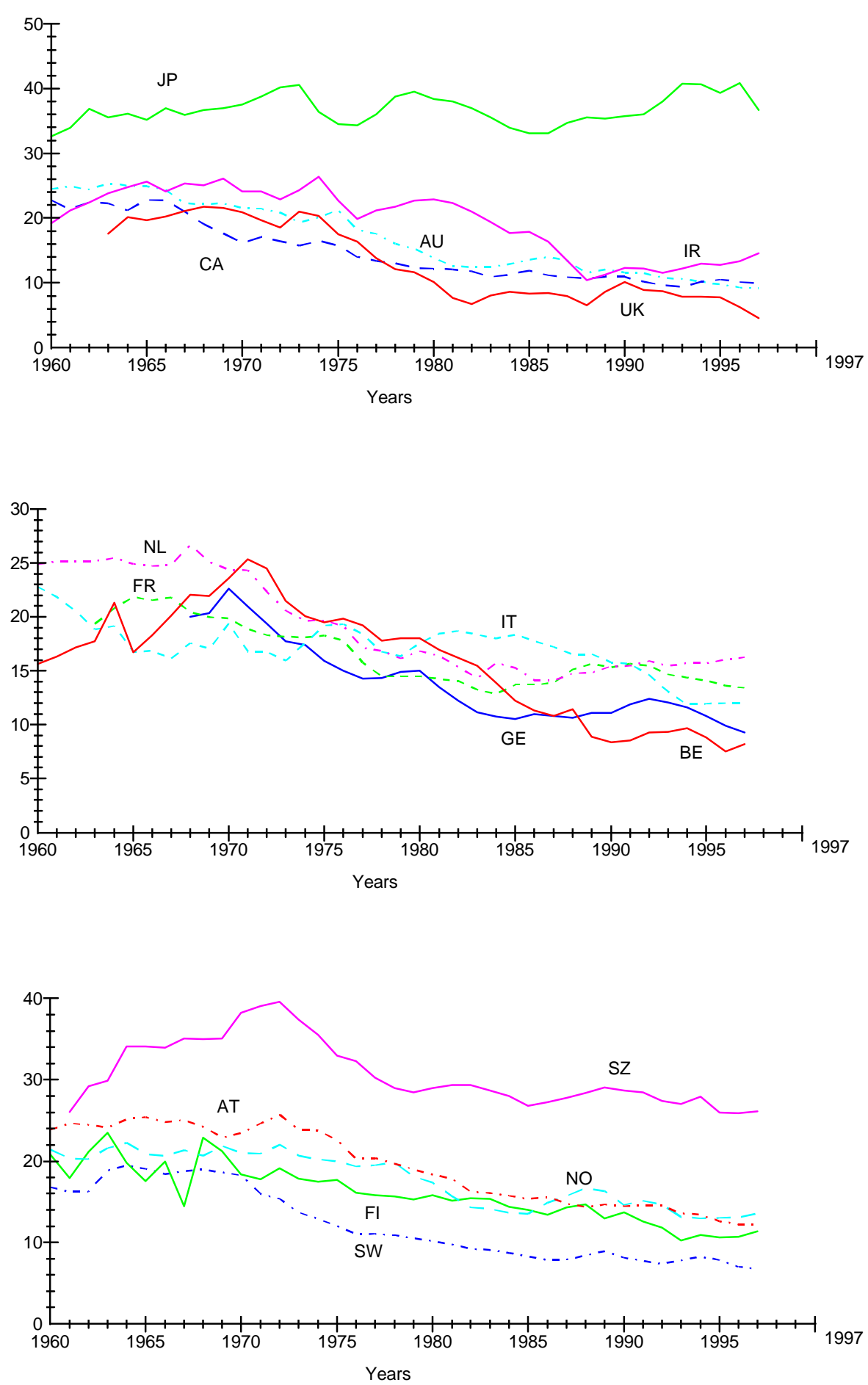

Source: OECD Economic Outlook - Compendium CD 1998/1 
1987-89), and it has been pointed out by Alesina and Perotti $(1996,1997)$ that most successful (i.e. long-lasting) fiscal adjustments tend to concentrate on cutting government transfers and consumption whilst most unsuccessful fiscal adjustments tend to result from cuts in capital expenditures. They also report that, following successful adjustments, there is a tendency for private investments to boom ${ }^{9}$.

This rise in the share of government consumption in GDP (and the consequent fall in government investment) has coincided with a slow-down in productivity growth. Table 1 shows how labour productivity and total factor productivity growth has evolved for a number of OECD countries since the 1960s.

Table 1: Productivity in the Business Sector

\begin{tabular}{|l|ccc|ccc|}
\hline & \multicolumn{3}{|c|}{ Total Factor Productivity } & \multicolumn{3}{c|}{ Labour Productivity } \\
\hline & $1960-1973^{1}$ & $1973-1979$ & $1979-1996^{2}$ & $1960-1973$ & $1973-1979$ & $1979-1996$ \\
\hline $\mathrm{CA}$ & 1.1 & -0.1 & -0.6 & 2.5 & 1.1 & 0.9 \\
$\mathrm{JP}$ & 5.6 & 1.1 & 1.2 & 8.4 & 2.8 & 2.3 \\
$\mathrm{AU}$ & 2.2 & 1.2 & 0.9 & 3.1 & 2.5 & 1.3 \\
$\mathrm{GE}^{4}$ & 2.6 & 1.8 & 0.6 & 4.5 & 3.1 & 1.2 \\
FR & 3.7 & 1.6 & 1.3 & 5.3 & 2.9 & 2.2 \\
$\mathrm{IT}$ & 4.4 & 2.0 & 1.2 & 6.4 & 2.8 & 2.1 \\
$\mathrm{UK}$ & 2.8 & 0.7 & 1.2 & 4.2 & 1.6 & 1.7 \\
$\mathrm{IR}$ & 4.6 & 3.9 & 3.6 & 4.8 & 4.3 & 4.1 \\
$\mathrm{BE}$ & 3.8 & 1.3 & 1.0 & 5.2 & 2.7 & 1.9 \\
$\mathrm{NL}$ & 3.5 & 1.7 & 1.0 & 4.8 & 2.6 & 1.5 \\
$\mathrm{NO}$ & 3.2 & 1.3 & 0.6 & 3.8 & 2.7 & 1.8 \\
SW & 1.9 & 0.0 & 1.2 & 3.7 & 1.4 & 2.0 \\
FI & 4.0 & 1.9 & 2.6 & 5.0 & 3.2 & 3.6 \\
SZ & 1.5 & -0.7 & -0.1 & 3.3 & 0.8 & 0.4 \\
$\mathrm{AT}$ & 3.2 & 1.1 & 1.0 & 5.7 & 3.1 & 2.3 \\
\hline
\end{tabular}

Notes:

11960 or earliest year available: IR 1961; JP UK 1962; FR SW 1965; CA AU NO 1966; NL 1969; BE 1970.

21996 or latest year available: AT NO 1994; IT AU FI IR SZ 1995.

3 Norway: mainland business sector - excludes shipping and crude petroleum and gas extraction.

4 Germany: Pre-1979 is W.Germany, 1979-96 is calculated as the average of W.German productivity growth between 1979 and 1991 and total German productivity growth between 1991 and the most recent year available.

5 Labour Productivity is output per employed person. TFP growth is a weighted average of growth in labour and capital productivity. Sample-period averages for capital and labour shares are used as weights.

Source: OECD Economic Outlook June 1998 (Annex Table 59).

\footnotetext{
${ }^{9}$ For an outline and evidence of possible non-Keynesian effects of fiscal expansions and contractions (particularly involving government consumption), see Giavazzi and Pagano (1990, 1995).
} 
Obviously one has to be careful in interpreting any causal links, but in a number of countries there has been a renewed emphasis on changing fiscal policies to 'take a longer term view', and this generally involves a reallocation towards capital expenditures. In the UK, the first Budget of the new Labour government brought with it a commitment towards a 'golden rule' of public spending, whereby deficit spending would only be allowed (over the cycle) on public investment. It remains to be seen how effective such measures are, as 'golden rules' for fiscal policy have been circumvented in the past (cf. the case of Germany), but the conventional wisdom is that long-term economic success requires a reallocation of government spending towards public investment.

There is one missing empirical link in this account: that which runs from political instability to government spending decisions. Here one has to rely on more qualitative evidence. Most of the empirical evidence on the links between political complexion of governments tends to focus on the impact of political uncertainty on fiscal deficits or total government spending (see Roubini and Sachs, 1989a,b, Grilli et al., 1991, and Alesina and Perotti, 1996). The general findings are that coalition governments tend, with some exceptions, to be less fiscally responsible ${ }^{10}$.

Data is of course available on the frequency of government changes and the complexion of the incumbent government in OECD countries which are nonpresidential democracies (see Woldendorp et al., 1993). However, one difficulty in measuring the degree of political uncertainty from the frequency of 'government changes' which have occurred ex post is that this does not provide a measure of the ex ante degree of political uncertainty and external competition experienced by the incumbent government during its term of office. Mid-term elections where these take 
place and regular opinion polls may provide a better guide to the changing pattern of electoral preferences. Furthermore, the frequency of government changes are not always a good guide to political stability in non-majoritarian systems, where fragmented coalitions have tended to be the norm, and political uncertainty and competition between parties tends to be internalised within coalition bargains.

However, even with this limited data at our disposal, it is generally true that since the late 1960s many OECD countries were characterised by periods of greater political uncertainty and competition between political parties, as governments which were previously single-party increasingly had to resort to coalitions and the frequency of shifts in the political complexion of governments increased. Even in countries where the 1980s and 1990s saw a period of single-party dominance (e.g. the UK), arguably there was an increased degree of political competition around the time of elections on fiscal matters. In some countries this took the form of a shift towards lower personal taxation (e.g. the UK), whilst in others it resulted in an unwillingness to take difficult decisions on government transfers and consumption spending (e.g. Italy, France).

We have extended the Woldendorp et al. data to 1998 using more recent election result data ${ }^{11}$, and we have constructed a number of additional indices of political fragmentation/instability for different decades of our sample. Of the various measures of political instability in popular use, many are largely determined by the electoral system in each country and exhibit less variation over time, these include the effective number of parties in government (see, for example, Laakso and Taagepera (1979)) and the number of types of government (e.g. single party majority, majority coalitions, etc.) which held office during the decade. Here we focus on two indicators of

\footnotetext{
${ }^{10}$ See also Dalle Nogare (1997).
} 
instability, the number of changes in government complexion over the decade (DCPG) based on the Woldendorp et al. CPG index; and the percentage of seats held by the governing party or coalition averaged over each decade (GSE), which is an inverse measure of instability.

Using decade-average data for the ratio of government investment to total government spending and for the DCPG, GSE variables, we obtained the following simple OLS regression results. Each regression involves data from 15 countries pooled over four decades, so there are 60 observations in total. Intercept dummies (D60s, D70s and D80s) were added for the different decades.

\section{Table 2: OLS Regression Results}

The dependent variable is Government Investment as a Proportion of Total Government Spending.

\begin{tabular}{|c|c|c|c|c|c|c|c|}
\hline & Intercept & D60s & D70s & D80s & GSE & DCPG & $\mathrm{R}^{2}$ \\
\hline 1. & 1.60 & 7.43 & 6.32 & 1.30 & 0.23 & - & 0.303 \\
& $(.316)$ & $(3.06)$ & $(2.66)$ & $(.55)$ & $(2.58)$ & & \\
\hline 2. & 17.18 & 7.94 & 7.35 & 2.19 & - & -2.65 & 0.283 \\
& $(9.08)$ & $(3.39)$ & $(3.13)$ & $(0.94)$ & & $(3.04)$ & \\
\hline 3. & 5.713 & 6.93 & 7.15 & 1.83 & 0.20 & -2.42 & \\
& $(1.12)$ & $(3.03)$ & $(3.17)$ & $(0.82)$ & $(2.88)$ & $(2.40)$ & 0.339 \\
\hline
\end{tabular}

The results show a significant inverse correlation between the proportion of government spending dedicated to investment and the degree of political instability.

In what follows we present a theoretical model in which electoral competition, through polarised partisan political preferences can impact on government spending and investment decisions and hence on long-run economic growth. To keep our model simple and in common with similar approaches (see Persson and Tabellini, 1998) we ignore the issue of debt accumulation by assuming that all government spending is

\footnotetext{
${ }^{11}$ Consistent government investment and productivity data are only available from the 1960 , hence our regression results begin in 1960. Political data were updated using Mackie and Rose $(1991,1997)$ and election Web sites www.agora.stm.it and www.ipu.org.
} 
financed from current taxation ${ }^{12}$. What our model explains is how and when an increase in political uncertainty may impact negatively on economic growth, and how partisan preferences may affect the efficiency of the economic outcome in terms of the median voter. As we shall see, the model provides an explanation for the link between political uncertainty, the increase in the share of government consumption in overall fiscal spending, and slower growth.

\section{A Theoretical Model.}

Our model is a simple model with government spending and endogenous growth. The government is assumed to tax the final output of producers. Tax revenues are then allocated between government consumption (which increases the current utility of consumers), and government investment, which encourages future growth and benefits consumers in the future. The tax rate and the allocation of government spending between public consumption and investment is determined at each point in time by the incumbent government.

Consumers in the economy are assumed to differ in their rate of time preference, with some consumers benefiting more than others from future consumption ${ }^{13}$. Consumers' political attitudes are captured by their rate of time preference: more patient consumers prefer higher tax rates and the allocation of a larger fraction of tax revenues to government investment.

We assume a standard partisan-type political economy model, in which there are two political parties, whose preferences are exogenously given at the outset. Each

\footnotetext{
${ }^{12}$ The presence or absence of debt only matters in models in which there are non-Ricardian effects, which is not the case here.

${ }^{13}$ In a richer model one might want to explain the source of these differences in consumers' time preference. These might arise because of the presence or absence of intergenerational links in a model
} 
party's political platform is given by the rate of time preference at which future benefits are capitalised. Consumers will vote for the party which most closely represents its views, and, by assuming a majoritarian political system, the elected party will enact its preferred policies. As in all standard partisan political models, we have to introduce an element of political uncertainty, which we do by assuming that the median voter's time preference fluctuates over time ${ }^{14}$.

Before outlining and analysing our model, we summarise the key results which emerge. First, the presence of political uncertainty creates policy myopia. Compared with consumers who share the identical rate of time preference, political parties always adopt policies which give rise to lower growth and a higher fraction of revenues spent on public consumption. Second, a higher degree of political uncertainty has both negative and positive effects on the growth rate (via the tax policies chosen by the political parties). However, the net effect of increased political uncertainty is that it discourages growth and increases the share of government consumption. Third, given the distribution of consumer preferences, we can assess the economic efficiency of the decisions made by the political parties. When compared to the median voter's preferences, the resulting equilibrium is generally inefficient. It turns out that the economy may grow too fast or too slowly, and the fraction of expenditures allocated to public consumption may be too high or too low.

with overlapping generations as opposed to infinitely-lived consumers (as assumed here). But, as long as there is some political uncertainty in the model, our conclusions would still hold.

${ }^{14}$ As in standard models, this can be either due to random voter turnout, or to shifts in the composition and preference distribution of the electorate (see Alesina and Rosenthal, 1995). 


\subsection{The Production and Government Sectors}

We assume a continuous-time ${ }^{15}$ model, in which the final output sector is perfectly competitive and there is no private capital ${ }^{16}$. The aggregate production function is:

$$
Y_{t}=\left(A_{t} L\right)^{\alpha}\left(G_{t} D\right)^{1-\alpha}
$$

where $Y_{t}$ is final output (a numeraire), $L$ is the working population (which we normalise to one), $D$ is 'land', which is equally owned by consumers and is again normalised to one. Productivity is augmented through the variable $A_{t}$, which captures a learning-bydoing effect, and through the flow of public investment, $G_{t}$ (where we assume that there is no congestion).

The government taxes final output at a rate $0<\tau<1$, and the first order conditions are:

$$
\begin{aligned}
& w_{t}=(1-\tau) \alpha A_{t} x_{t}^{1-\alpha} \\
& q_{t}=(1-\tau)(1-\alpha) A_{t} x_{t}^{1-\alpha}
\end{aligned}
$$

where $x_{t}=\left(G_{t} / A_{t}\right), w$ is the wage rate and $q$ is the rental rate of land.

The variable $A_{t}$ captures an external learning-by-doing effect. In line with standard endogenous growth models, we assume that $A_{t}$ is proportional to the accumulation of output production per worker:

$$
A_{t}=b \int_{0}^{t} Y_{s} d s
$$

where $b>0$ is the degree of the learning-by-doing effect. From (4), using (1) we have:

$$
\left(\frac{\dot{A}}{A}\right)_{t}=\left(\frac{b Y}{A}\right)_{t}=b x_{t}^{1-\alpha}
$$

\footnotetext{
${ }^{15}$ This turns out to be a convenient way to derive the growth equilibrium conditions in an infinitehorizon model. As we shall see below, this involves us modelling government changes as a Markov process. However, it turns out that it changes in the degree of political uncertainty can be modelled quite easily in a continuous-time context.

${ }^{16}$ This assumption is not particularly restrictive and is common to many endogenous growth models.
} 
Turning now to government spending ${ }^{17}$, a fraction of this $(0<\theta<1)$ is allocated to public investment, and the remainder is used for public consumption, $Z_{t}$ :

$$
\begin{aligned}
& G_{t}=\theta \tau Y_{t} \Rightarrow \theta \tau=x_{t}^{\alpha} \\
& Z_{t}=(1-\theta) \tau Y_{t}=(1-\theta) \tau A_{t} x_{t}^{1-\alpha}
\end{aligned}
$$

As we shall see below, government consumption directly enters consumers' utility function, and the policy parameters $\tau, \theta$ will be determined endogenously by the political parties.

We can now derive the growth equilibrium. The production function implies that the growth rate, $g$ is:

$$
g \equiv\left(\frac{\dot{Y}}{Y}\right)_{t}=\left(\frac{\dot{A}}{A}\right)_{t}+(1-\alpha)\left(\frac{\dot{x}}{x}\right)_{t}
$$

Note from (6) that $x_{t}$ is constant as long as $\theta \tau$ is fixed. Hence, the growth rate will jump whenever there is a (stochastic) change of government which causes a change in $\theta$ and $\tau$. During the period between two successive switches in the fiscal policy parameters, we have:

$$
g \equiv\left(\frac{\dot{Y}}{Y}\right)_{t}=\left(\frac{\dot{A}}{A}\right)_{t}=b x^{1-\alpha}=b(\theta \tau)^{(1-\alpha) / \alpha}
$$

using (6) and (7).

This is the economic equilibrium condition. Note that the growth rate is monotonically increasing in the tax rate, unlike models with private capital where $g$ would be nonmonotonic (see, e.g. Barro, 1990).

\footnotetext{
${ }^{17}$ For simplicity we ignore the issue of deficit financing. Normally deficit financing would not be an issue in any case in a model with infinitely-lived consumers, but the existence of different time preferences between the median voter and the incumbent government raises some potentially interesting issues of how different types of government spending might be financed (including the issue of 'golden rules' for public spending). But these issues are not central to our concerns in this paper.
} 


\subsection{Voters Preferences and Behaviour}

As noted earlier, we assume that consumers are infinitely lived, and differ in their rate of subjective time preference, $\rho$. This parameter summarises their political preferences: consumers with a lower value of $\rho$ give greater weight to future consumption and therefore tend to support a growth-oriented party. We assume that the distribution of preferences is such that $\rho \in[\rho, \bar{\rho}]$ and $\rho<\rho<\bar{\rho}$ is continuously distributed with the distribution function $\mathrm{F}($.$) .$

The consumers' intertemporal and instantaneous utility functions are given by:

$$
\begin{aligned}
& U_{t}=\int_{t}^{\infty} e^{-\rho(s-t)} u\left(c_{s}, Z_{s}\right) d s \\
& u\left(c_{s}, Z_{s}\right)=c_{s}^{\beta} Z_{s}^{1-\beta}
\end{aligned}
$$

where $c_{s}$ is the consumption of final output and $Z_{s}$ is the consumption of government services. As there is no capital, consumers will spend their disposable income in each instant on private consumption, i.e.:

$$
c_{t}=w_{t}+q_{t}=(1-\tau) A_{t} x_{t}^{1-\alpha}
$$

Note that (7) and (10) can be rewritten as:

$$
\begin{aligned}
& c_{t}=\alpha A_{t}(1-\tau)(\theta \tau)^{(1-\alpha) / \alpha} \\
& Z_{t}=(1-\theta) \tau A_{t}(\theta \tau)^{(1-\alpha) / \alpha}
\end{aligned}
$$

Note that taxation reduces private consumption and boosts public consumption for a given value of $A_{t}$. A higher tax rate will boost both types of consumption through its positive impact on public investment (captured by the factor $(\tau)^{1-\alpha / \alpha}$ ). Note also that private consumption for all consumers is maximised at $\tau=1-\alpha$. However, consumers are not only interested in current consumption, and as a higher tax rate implies a higher 
growth rate, consumers generally prefer a higher tax rate than $(1-\alpha)$, with the ideal tax rate higher for the more patient consumers (i.e. those with a lower $\rho$ ).

As we shall see below, different political parties differ in their fiscal policies. Consumers will generally vote for the party whose policy yields the highest utility. We begin by characterising each consumers ideal policies $\tau$ and $\theta$ (and hence $g$ ). As we are dealing with an infinite-horizon model, when consumers vote, they are fully committed to the policy of their chosen party (i.e. they compare their level of utility under both parties assuming that the policy will remain in place for an infinite horizon). Substituting (11) and (12) into (9), and re-expressing the resulting equation using (8):

$$
U_{t}(\rho, \tau, g)=\frac{A_{t}(1-\tau)^{\beta}\left[\tau-(g / b)^{\alpha / 1-\alpha}\right](g / b)}{\rho-g}
$$

where we assume that $\rho>g$. By differentiating (13) we obtain the optimal fiscal policy for the consumer, given his/her value of $\rho$. (Note that from (8), knowing the optimal value of $g$, one can find the optimal value of $\theta$, given $\tau$ ). This illustrates the various trade-offs faced by consumers. The optimal values of $\tau$ and $g$ (and hence $\theta$ ) are determined implicitly by:

$$
\begin{gathered}
\frac{\partial U_{t}}{\partial \tau}=0: \quad \tau=\beta(g / b)^{\alpha / 1-\alpha}+(1-\beta) \\
\frac{\partial U_{t}}{\partial g}=0: \quad\left\{\left[(1-\beta) \frac{\alpha}{1-\alpha}+1\right]\left(\frac{g}{b}\right)^{\alpha /(1-\alpha)}-\tau\right\}(\rho-g)=g\left[\tau-\left(\frac{g}{b}\right)^{\alpha /(1-\alpha)}\right]
\end{gathered}
$$

Equation (14) shows that as the tax rate increases private consumption falls due to the distortionary tax effect and this has a negative impact on utility, but public consumption increases due to higher tax revenues, which positively affects utility. The positive relationship between the tax rate and growth in (14) is due to the fact that with a greater proportion of resources dedicated to public investment (and higher growth), consumers 
are more willing to endure higher taxes. Equation (15) shows that as the growth rate rises the level effect of higher public investment on output raises private consumption and current utility, whilst future utility increases because of the prospective rise in future private and public consumption. However, less is spent on public consumption and this has a negative impact on consumers utility. Combining (14) and (15) summarises these trade-offs:

$$
\underbrace{\frac{g^{\alpha /(1-\alpha)}}{1-\alpha}}_{M C}=\underbrace{\frac{\alpha}{1-\alpha} \frac{g^{1 /(1-\alpha)}}{\rho}+b^{\alpha /(1-\alpha)}}_{M B}
$$

The LHS of (19) shows the marginal cost to consumers of increasing the growth rate, and the RHS shows the marginal benefit of increasing the growth rate. We are now able to state:

LEMMA 1 (i) Consumers' ideal g is uniquely determined in (16), and (ii) and interior solution to (16) exists for $\rho>b$.

Proof. Note that the LHS and RHS of (16) are monotonically increasing in g; also $(\partial M C / \partial g) /(\partial M B / \partial g)=(\rho / g)$, which implies that the MC curve is always steeper than the MB curve for $g \in(0, \rho)$ (as shown in Figure 1).Moreover, $M B-M C=b^{\alpha / 1-\alpha}>0$ at $g=0$ and $M C-M B=(\rho / b)^{\alpha / 1-\alpha}-1$ at $g=\rho$. Therefore a unique interior solution exists for $(\rho / b)>1$.

\section{Figure 1:}

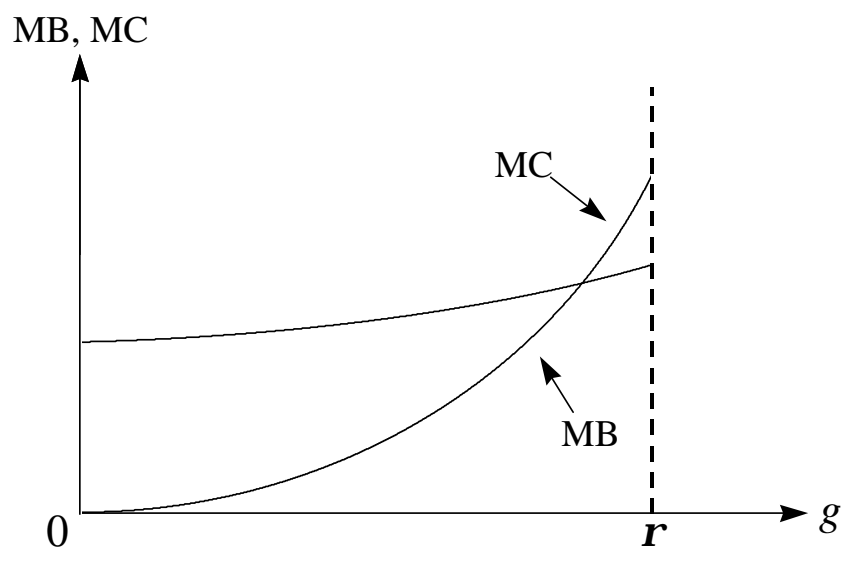


We are now also in the position of defining the relationships between the consumers' rate of time preference and their preferred fiscal policies (and growth rate):

LEMMA 2 The Consumers' ideal $\tau$, $\theta$, and $g$ are characterised by the following functions:

$$
\begin{aligned}
& g=g(\rho), \quad g^{\prime}<0 \\
& \tau=\tau(\rho), \quad \tau^{\prime}<0 \\
& \theta=\theta(\rho), \quad \theta^{\prime}<0
\end{aligned}
$$

Proof. In Figure 1, a higher value of $\rho$ shifts down the MB curve, leading to a lower growth rate. In addition, from (14) we know that $g$ and $\tau$ are positively related. Moreover, using (8), equation (14) can be rewritten as:

$$
\theta=\frac{1}{\beta}\left[1-\frac{(1-\beta)}{\tau}\right]
$$

so that $\tau$ and $\theta$ are also positively related as long as $\tau>1-\beta$, which we assume here ${ }^{18}$.

A corollary of Lemmas 1 and 2 is the following:

COROLlaRY 3. Consumers with a relatively high (low) $\rho$ will vote for a party whose policy generates a low (high) $\tau, \theta$ and $g$.

This is because the utility of consumers with time preference $\rho$ is single-peaked in $g$, and achieves a maximum at $g=g(\rho)$.

\subsection{Political Parties, Political Uncertainty and Policies.}

We now turn to the preferences of the political parties in our partisan model. We assume that there are two political parties, whose political platforms are summarised by their rate of time preference, $\rho$, with $\rho_{H}$ for party $\mathrm{H}$ and $\rho_{L}$ for party $\mathrm{L}$ such that $\rho_{H}>\rho_{L}$. Hence, party $\mathrm{L}$ is relatively more 'growth-oriented' than party $\mathrm{H}$ in that it gives greater weight to future levels of consumer utility. However, it is important to note that party L may not necessarily adopt policies which bring about a higher growth

\footnotetext{
${ }^{18}$ This assumption makes sense and is required for an interior solution, given the Cobb-Douglas form of our instantaneous utility function, as otherwise it would imply that the elasticity of utility with respect to public consumption would be so great as to swamp the benefits from greater public investment. It would then be optimal for consumers to prefer no resources to be allocated to public investment.
} 
rate in equilibrium. The policy outcomes will depend critically on the nature of the political party's utility function, which will depend on the role played by office motivation, and hence by political uncertainty.

As explained above, we follow the standard political economy literature on partisan models by assuming a majoritarian system, where the incumbent party has total control on fiscal policy ${ }^{19}$. We will denote the two parties' policies as $\left(\tau_{i}, \theta_{i}\right), \quad i=L, H$, which will lead to outcome $g_{i}$ for growth. These policy outcomes will of course be determined endogenously, as shown below. Taking the policy pairs $\left(\tau_{i}, \theta_{i}\right)$ as given, consumers will decide whether to vote for party $\mathrm{H}$ or $\mathrm{L}$.

To facilitate our analysis of voters' behaviour we shall assume for the moment that party $\mathrm{H}$ will deliver a lower growth rate than party $\mathrm{L}\left(g_{H}<g_{L}\right)$. The conditions under which this will be the case will be derived formally below. In this case, it is apparent that voters with a higher value of $\rho$ will vote for party $H$ and those with a lower value of $\rho$ will vote for party $L$. In what follows, let $\tilde{\rho}$ denote the time preference of the threshold voters, who are indifferent between supporting party $\mathrm{H}$ and party $\mathrm{L}$ (i.e. the policies of both parties will yield them the same utility):

$$
U_{t}\left(\tilde{\rho}, \tau_{L}, \theta_{L}\right)=U_{t}\left(\tilde{\rho}, \tau_{H}, \theta_{H}\right)
$$

Elections are assumed to take place at each instant ${ }^{20}, t$. As in standard partisan political economy models, political uncertainty derives from stochastic fluctuations in the voters' distribution function $F(\rho)$, either because of random voter turnout, or variations in the composition of the voting population. Hence an incumbent political party faces the risk

\footnotetext{
${ }^{19}$ One potential extension of our model, which we do not explore here for reasons of space, is that the minority party may also have some control on fiscal policy through a bargaining framework (see for example Rogoff, 1990).

${ }^{20}$ As noted previously our conclusions would not be affected by considering a discrete-time version of the model in which elections are held in every period. Our continuous-time set-up merely makes the analysis of our endogenous-growth model easier.
} 
of being replaced by the opposition party. More specifically, we assume that at any point in time the distribution function takes the following two functional forms:

$$
F(\rho)=\left\{\begin{array}{l}
F_{l}(\rho) \\
F_{h}(\rho)
\end{array}\right.
$$

Next, let $\rho_{l}$ and $\rho_{h}$ denote the rates of time preference of the median voters associated with each distribution function, i.e. $F_{l}\left(\rho_{l}\right)=F_{h}\left(\rho_{h}\right)=1 / 2$. The only condition which we impose on the distribution function is ${ }^{21}$ :

$$
\rho_{l}<\tilde{\rho}<\rho_{h}
$$

Figure 2 illustrates the possible form of the density functions associated with these distribution functions.

\section{$\underline{\text { Figure } 2}$}

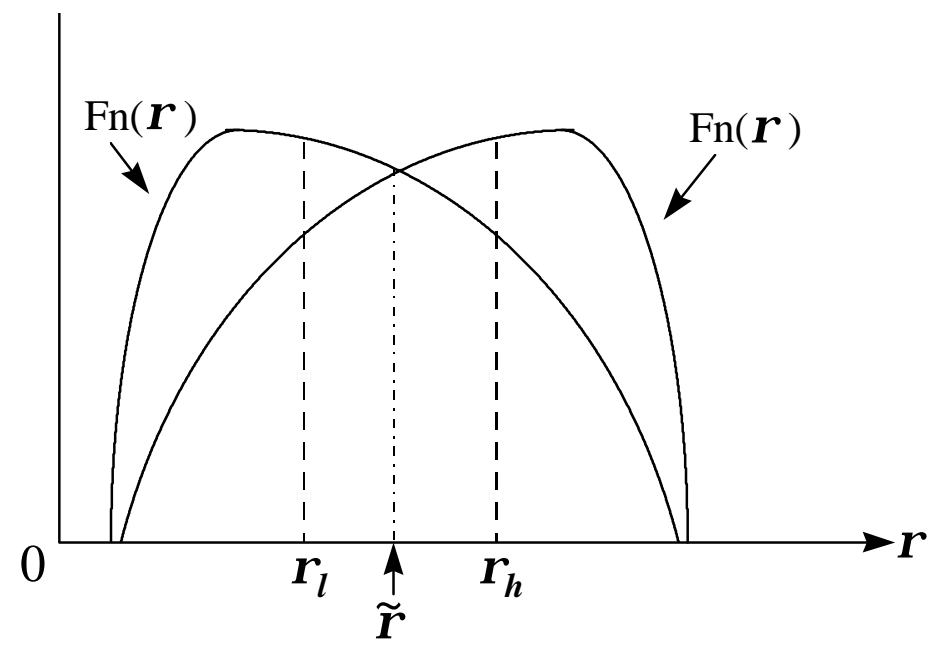

It should be apparent that, when the distribution function is given by $F_{l}(\rho)$, party $\mathrm{L}$ will win the election, and when the distribution function switches to $F_{h}(\rho)$, party $\mathrm{H}$ will be in office. The measure of consumers who will vote for party $\mathrm{L}$ and $\mathrm{H}$ under these two scenarios is given by:

\footnotetext{
${ }^{21}$ It does not matter if there is a shift in either of the supports of the distribution.
} 


$$
\begin{aligned}
& N_{L}=F_{l}(\tilde{\rho})>F_{l}\left(\rho_{l}\right)=1 / 2 \\
& N_{H}=1-F_{h}(\tilde{\rho})>1-F_{h}\left(\rho_{h}\right)=1 / 2
\end{aligned}
$$

The degree of political uncertainty can be modelled by assuming that the stochastic change between the two distribution functions follows a Markov process, i.e.:

$$
\begin{aligned}
& F_{l}(\rho) \rightarrow F_{h}(\rho) \text { with a flow probability } \eta \\
& F_{h}(\rho) \rightarrow F_{l}(\rho) \text { with a flow probability } \lambda
\end{aligned}
$$

Note that by setting $\eta=\lambda$ we have a similar situation to one in discrete time where both parties have an equal chance of being elected. An increase in these flow probabilities will increase the degree of political uncertainty because it will lead to a greater number of government changes.

Next we turn our attention on the incentives faced by each party $i$ in deciding on its policy set. We assume that each party maximises the sum of the utility functions of the consumers who support it, i.e. the instantaneous pay-off is $N_{i} u(c, Z)$. However, we also assume that each party is office-motivated, in that it gains a zero pay-off when it is out of office ${ }^{22}$. We can now write down the Bellman equations for each party $i$ :

$$
V_{i}(A)=\max _{\tau, g}\left\{N_{i} u(c, Z) d t+\left(1-\rho_{i} d t\right)\left[V_{i}(A+g A d t)\left(1-p_{i} d t\right)+\hat{V}_{i}(A+g A d t) p_{i} d t\right]\right\}
$$

where $V_{i}\left(A_{t}\right)$ is the value function which party $i$ achieves when it is in office, and $\hat{V}_{i}\left(A_{t}\right)$ when it is out of office, and $p_{i}$ is defined as the flow probability of losing the current election (i.e. $p_{L}=\eta, p_{H}=\lambda$ ). Note from (26) that the state variable is $A$, so that when a party is elected, it gains utility $N_{i} u(c, Z)$ during interval $d t$. But during this

\footnotetext{
${ }^{22}$ There are different ways of introducing office motivation in a political party's pay-off function (see Rogoff, 1990, Persson and Tabellini, 1990, 1998). In models where elections have a disciplining effect on incumbent governments one can introduce office motivation as a fixed benefit from being in office, or fixed cost from being out of office. But our purpose here is to show how policy myopia can arise in a partisan model, and policy myopia effects will emerge as long as the political benefits to a party from being in office are related to the policy actions taken. Thus, for instance, our results would still hold in a model where each party derives some benefit when it is out of office from the policies undertaken, as long as the benefits when in office depend in some measure on the utility of the consumers who elected
} 
time interval, the technological level of the economy will have improved by $g A d t$, which enters the value function at the end of the time interval. At that time, party $i$ will still be in office with a probability of $\left(1-p_{i} d t\right)$, achieving $V_{i}(A+g A d t)$, or will lose the election with a complementary probability $p_{i} d t$, attaining $\hat{V}_{i}(A+g A d t)$.

Of course, unlike a two-period model, in our infinite-horizon model a party which loses office may always expect to return to office at some future date and its current policies will therefore have an impact on future pay-offs even after losing an election. This will therefore need to be taken into account in computing $\hat{V}_{i}(A)$, and the stochastic steady-state equilibrium of the model. We can determine $\hat{V}_{i}(A)$ by the following recursive equation:

$$
\hat{V}_{i}(A)=\left(1-\rho_{i} d t\right)\left[\hat{V}_{i}(A+g A d t)\left(1-q_{i} d t\right)+V_{i}(A+g A d t) q_{i} d t\right]
$$

where $q_{i}$ is the flow probability of winning in the current election and is defined as $\left(q_{L}=\lambda, q_{H}=\eta\right)$. From (24) we see that when party $i$ is not in office, at the end of time interval $d t$ it will still not be elected with probability $\left(1-q_{i} d t\right)$, attaining $\hat{V}_{i}$, or it will be elected with a complementary probability $q_{i} d t$, attaining $V_{i}$.

In order to find the optimal fiscal policies by the two parties, we can differentiate (23), holding $\hat{V}_{i}$ as given. The first-order conditions are:

$$
\begin{aligned}
& \tau_{i}=\beta\left(\frac{g_{i}}{b}\right)^{\alpha / 1-\alpha}+1-\beta \\
& V_{i}^{\prime}(A)=\frac{\psi N_{i}}{b}\left(\frac{g_{i}^{\alpha / 1-\alpha}}{1-\alpha}-1\right)
\end{aligned}
$$

where $i=H, L$ and $\psi \equiv \beta^{\beta}(1-\beta)^{1-\beta}$. 
We can compare (25) and (26), the chosen policies of the two parties with the optimal tax and expenditure allocation (growth) policies from the point of view of consumers with the same rate of time preference (equations (14) and (15)). Whilst (25) is identical to (14), (26) differs from (16). This implies that the fiscal policies of each political party does not match those of consumers with the same political stance as the two parties. We shall return to this point below.

\subsection{The Stochastic Steady State Growth Equilibrium under Political Uncertainty}

Having characterised the policy choices of each political party, and the working of our endogenous growth model, we are now in a position to solve for the stochastic steadystate equilibrium of our model.

We know that in equilibrium:

$$
V_{i}(A)=V_{i}^{o} A \quad i=H, L
$$

So that (26) now becomes:

$$
V_{i}^{o}=\frac{\psi N_{i}}{b}\left(\frac{g_{i}^{\alpha / 1-\alpha}}{1-\alpha}-1\right)
$$

Letting $d t \rightarrow 0$ in the Bellman equations (23) and (24) and rewriting the resulting equations with (27) and (28), we obtain the stochastic steady-state growth equilibrium under the two regimes $(\mathrm{G})$ :

$$
\underbrace{\frac{g_{i}^{\alpha /(1-\alpha)}}{1-\alpha}}_{M C}=\underbrace{\frac{\alpha}{1-\alpha} \frac{g_{i}^{1 /(1-\alpha)}}{\rho_{i}+\Gamma_{i}\left(g_{i}\right)}+b^{\alpha /(1-\alpha)}}_{M B}
$$

where $\Gamma_{L}\left(g_{L}\right)=\frac{\eta\left(\rho_{L}-g_{L}\right)}{\lambda+\rho_{L}-g_{L}}, \quad \Gamma_{H}\left(g_{H}\right)=\frac{\lambda\left(\rho_{H}-g_{H}\right)}{\eta+\rho_{H}-g_{H}}$

This expression shows the marginal costs and benefits to each party of increasing the growth rate, and exactly parallels equation (16), which showed the voters' preferred 
growth rate. It can be readily seen that, unlike the consumers' ideal choice for $g$, the political parties' decision is affected by the presence of the extra term $\Gamma_{i}\left(g_{i}\right)$ : these capture the effect of policy uncertainty which generates a degree of policy myopia.

Before discussing the policy myopia effect in detail, we first have to establish the following proposition:

Proposition 4 (i) The growth rate generated by party i's fiscal policies is uniquely determined in $(G)$ and $(i i)$ and interior solution to $(G)$ exists for $\rho>b$.

Proof. Note that $\Gamma_{i}^{\prime}(g)<0$, so that the MB curve is monotonically increasing in $g \in(0, \rho)$. In addition, $\Gamma_{i}(g)>0$ for $g \in(0, \rho)$ and $\Gamma_{i}(g)=0$ at $g=0$ and $g=\rho$. Hence, the MB curve associated with $(\mathrm{G})$ is located entirely below the MB curve in (16), except for $g=0$ and $g=\rho$ where they coincide. Hence, as shown in Figure 3, a unique interior solution exists for $\rho>b$.

\section{Figure 3:}

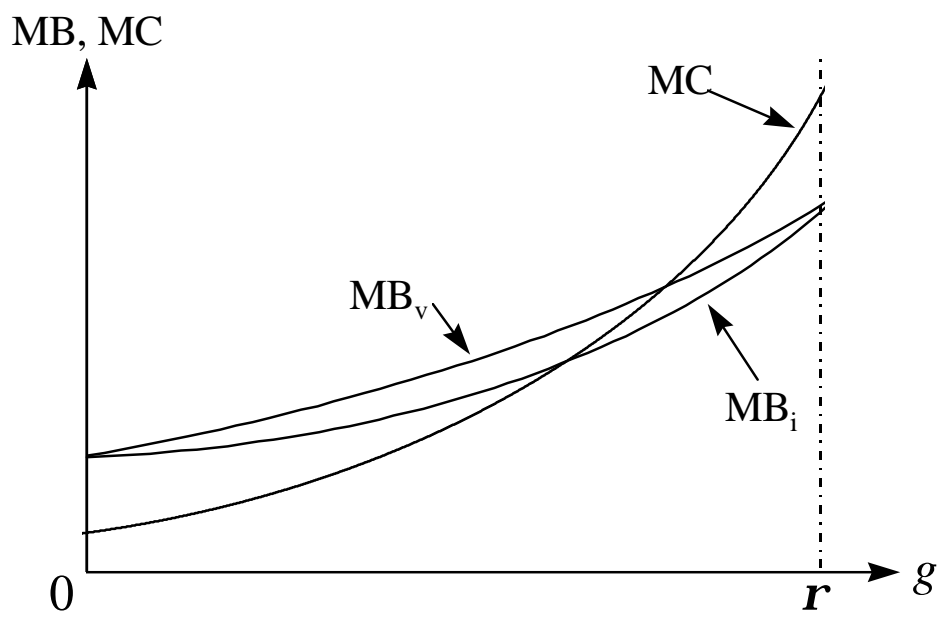

where $M B_{i}$ represents the marginal benefit to party $i$ and

$\mathrm{MB}_{\mathrm{v}}$ represents the marginal benefit to a voter with the same $\rho$ as party $i$.

The policy myopia effect is due to the presence of political uncertainty, which means that the political parties have an uncertainty-adjusted discount rate, $\rho_{i}+\Gamma_{i}(g)$ which is higher compared to consumers with the same rate of time preference. That the growth rate chosen by party $i$ is not identical to the ideal $g$ chosen 
by consumers who share the same political preferences is apparent from Figure 3. The knowledge that party $i$ will lose office at some stage in the future creates this shortsightedness in policy. As the MB of party $i$ is always below that of consumers, the party's fiscal policy will be biased towards government consumption and against growth. This can be summarised as the following proposition:

Proposition 5 Political parties always set policies such that taxes are lower and the fraction of tax revenue spent on public consumption is higher than consumers with the identical rate of time preference.

The magnitude of the bias against growth-oriented fiscal policies caused by policy myopia obviously depends on the degree of political uncertainty. A higher value of $p_{i}$, the flow probability of losing office increases the myopia term, $\Gamma_{i}$, and hence the effective discount rate of the government. Interestingly, although a higher value of $q_{i}$, the flow probability of winning the next election after losing the current one tends to lower the value of $\Gamma_{i}$, as one might expect, it cannot eliminate the policy myopia effect. The effect only disappears as $q_{i} \rightarrow \infty$.

This begs the question of what the net effect will be on the average growth rate of changing the degree of political uncertainty, which is one of the key issues we wanted to address. A higher flow probability of the current incumbent losing the next election $\left(p_{i}\right)$, and a higher flow probability of party $i$ losing the next election given that it is not the current incumbent $\left(q_{i}\right)$ may both be seen as increasing political uncertainty but, as noted above, they have opposing impacts on the growth rate. Which effect dominates? The most sensible way to address this is by setting $p \equiv \lambda=\eta=p_{i}=q_{i}$, so that an increase in political uncertainty is not biased against a particular party (parties alternate in power more frequently, with neither party increasing its average share of time in office). Now each party has an equal chance of winning each election with the same 
flow probability. In these circumstances, it is straightforward to show that $\Gamma_{i}\left(g_{i}\right)$ rises as $p$ increases, so that the negative effect of political uncertainty on growth dominates. In this instance current fiscal policy is determined by the prospects of the outcome in the immediate election, and the prospect of being re-elected after losing is too distant in the future to matter significantly.

It is intuitively obvious that the average growth rate in the economy will also fall as political uncertainty increases. As party $L$ is in office with a flow probability of $\lambda$ and party $\mathrm{H}$ replaces it with a flow probability of $\eta$, the average growth rate in the economy is given by:

$$
g=\Lambda g_{L}+(1-\Lambda) g_{H}, \quad \Lambda=\lambda /(\lambda+\eta)
$$

Again, as above, we want to consider an increase in political uncertainty, $p$, where $p \equiv \lambda=\eta$. The average growth rate then becomes $g=\left(g_{L}+g_{H}\right) / 2$. We have already shown that a higher $p$ raises the policy myopia term $\Gamma_{i}\left(g_{i}\right)$, shifting the MB curve down with a lower $g$. Thus, the average growth rate unambiguously falls.

\subsection{Economic Efficiency}

Having established that greater political uncertainty leads to increased policy myopia and to lower growth, we also have to consider whether the steady-state stochastic political equilibrium described above is inefficient in terms of consumer welfare. We have already established that growth is lower than would be preferred by each party's natural constituency of voters.

With different preferences between consumers the issue has to be confronted as to what we mean by an 'efficient outcome'. The most natural metric to use is that of the 
median $\operatorname{voter}^{23}$. Suppose the median voter could choose a policy pair $(\tau, \theta)$. What equilibrium would emerge compared to the equilibrium discussed so far in (G)?

To do this we have to compare the outcome in $(G)$ with that which would prevail in a world where the median voter could determine their ideal fiscal policy. Of course in our model we assume that the median voter's time preference stochastically fluctuates between $\rho_{l}$ and $\rho_{h}$. The key issue is what drives these fluctuations. The trivial case is where these fluctuations are due purely to random voter turnout, and preferences remain unchanged in the underlying population, as the growth rate chosen by the two parties as they alternate in power will oscillate around the level which corresponds to that preferred by the median voter. However, if there are fluctuations in the preferences of the population as one might expect there to be over time, due to changes in demographic composition ${ }^{24}$, then with static political preferences in the two parties the issue of economic efficiency requires closer attention.

In this case fluctuations in the median voter's time preference will lead to fluctuations over time in the growth rate which they would prefer. From equation (16) this would be given by:

$$
\frac{g_{j}^{\alpha / 1-\alpha}}{1-\alpha}=\frac{\alpha}{1-\alpha} \frac{g_{j}^{1 / 1-\alpha}}{\rho_{j}}+b^{\alpha / 1-\alpha}, \quad j=h, l
$$

The average growth rate is:

$$
g^{m}=\Lambda g_{l}+(1-\Lambda) g_{h}
$$

Equations (29) and (30) imply:

\footnotetext{
${ }^{23}$ See Muscatelli (1998) for an example of a model where the economic efficiency of different regimes is evaluated with distributed preferences in a partisan model of monetary policy.

${ }^{24}$ Family composition and inter-generational utility linkages may also matter here. For instance, one might have expected voters in many Western economies in the 1950s and early 1960s after the postwar baby boom to be more interested in public investment and future growth than voters in the 1980s and 1990s, with the decline in population growth. These issues however would need to be addressed in a different model with overlapping generations.
} 


$$
g^{m}-g=\Lambda\left(g_{l}-g_{L}\right)+(1-\Lambda)\left(g_{h}-g_{H}\right)
$$

This allows us to state the following proposition and corollary:

Proposition 6 The political party equilibrium is generally inefficient, and the growth rate may be too high or too low compared to the preferred median voter outcome, i.e. $g^{m} \neq g$.

Proof. First note that the growth rate crucially depends on the discount rate that the median voter and the political parties use (see $(\mathrm{G})$ and (30)). Thus, whether $g_{l}>$ or $<g_{L}$ and $g_{h}>$ or $<g_{H}$ depends on the values of $\rho_{j}, j=l, h$ and $\rho_{i}+\Gamma\left(g_{i}\right), i=H, L$. There are four possible cases:

1. $\rho_{L}+\Gamma_{L}\left(g_{L}\right)<\rho_{l}<\rho_{h}<\rho_{H}+\Gamma_{H}\left(g_{H}\right) \Rightarrow g_{L}>g_{l}>g_{h}>g_{H} \Rightarrow g^{m}<$ or $>g$

2. $\rho_{l}<\rho_{L}+\Gamma_{L}\left(g_{L}\right)<\rho_{H}+\Gamma_{H}\left(g_{H}\right)<\rho_{h} \Rightarrow g_{l}>g_{L}>g_{H}>g_{h} \Rightarrow g^{m}<$ or $>g$

3. $\rho_{l}<\rho_{L}+\Gamma_{L}\left(g_{L}\right)<\rho_{h}<\rho_{H}+\Gamma_{H}\left(g_{H}\right) \Rightarrow g_{l}>g_{L}>g_{h}>g_{H} \Rightarrow g^{m}>g$

4. $\rho_{L}+\Gamma_{L}\left(g_{L}\right)<\rho_{l}<\rho_{H}+\Gamma_{H}\left(g_{H}\right)<\rho_{h} \Rightarrow g_{L}>g_{l}>g_{H}>g_{h} \Rightarrow g^{m}<g$.

COROLlaRY 7 The fiscal policies in these four cases are:

- Cases (1) and (2): $\tau^{m}>$ or $<\tau$ and $\theta^{m}>$ or $<\theta$

- Case (3): $\tau^{m}>\tau$ and $\theta^{m}>\theta$

- Case (4): $\tau^{m}<\tau$ and $\theta^{m}<\theta$

Proof These results follow directly from proposition 6 and (14) and (20).

Essentially the relationship between the outcome in the political equilibrium and the ideal outcome for the median voter depends on the positioning of the two political parties (which is exogenous in our model) relative to the fluctuating preferences of the median voter. Hence the outcome depends critically on the polarisation of political party preferences, and the swing in voters' political attitudes. This can be readily seen with the aid of Table 3.

Table 3: Deviation of Median Voter from Threshold Consumer

\begin{tabular}{|l|c|c|c|c|}
\hline & Case 1 & Case 2 & Case 3 & Case 4 \\
\hline$\left|\widetilde{\rho}-\left(\rho_{L}+\Gamma_{L}\right)\right|-\left|\tilde{\rho}-\rho_{l}\right|$ & + & - & - & + \\
\hline$\left|\widetilde{\rho}-\left(\rho_{H}+\Gamma_{H}\right)\right|-\left|\tilde{\rho}-\rho_{h}\right|$ & + & - & + & - \\
\hline
\end{tabular}


In the Table $\left|\tilde{\rho}-\left(\rho_{i}+\Gamma_{i}\right)\right|, \quad i=H, L$ is the deviation of the 'effective' discount rate of party $i$ from that of the threshold voter, and similarly $\left|\tilde{\rho}-\rho_{j}\right|, j=l, h$ measures the deviations of the discount rate of the median voter from the threshold consumer. Thus, for instance, $\left|\widetilde{\rho}-\left(\rho_{L}+\Gamma_{L}\right)\right|-\left|\tilde{\rho}-\rho_{l}\right|$ compares the degree of such deviations for the lower half of the distribution of $\rho$. If it is positive (negative), a swing of consumers' political attitudes is relatively small (large) relative to differences of discount rates of political parties.

Essentially therefore Cases (1) and (2) illustrate a situation in which fluctuations in consumers' preferences are relatively symmetric around the positions of the two political parties, whilst in Cases (3) and (4) the swings in voters' preferences are skewed relative to the political parties' positions.

In reality we might expect voters' preferences to show some persistence over time, as demographic influences have an impact on their desired fiscal policies. If it takes time for political parties to reposition themselves following a major voter realignment then it follows that the outcome will be inefficient from the point of view of the median voter. One can think for instance of a highly polarised system in which the two major political parties have widely different positions and where the outcome might involve less volatility in the growth rate (one party might even dominate on average over a period of time) but a highly inefficient outcome ${ }^{25}$ would result.

Suppose instead that one were to allow political parties to reposition themselves in the preference spectrum, in contrast to our simple model. In this case, the inefficiency of the outcome would tend to be reduced, as political parties try to follow the median voter in a 'Hotelling effect'. But providing they cannot do this perfectly, and providing 
some degree of political uncertainty remains, the policy myopia effect would still persist, and we would still expect a higher degree of uncertainty to reduce public investment and growth in equilibrium.

Before concluding, we need to address the assumption made so far that that party $\mathrm{H}$ will deliver a lower growth rate than party $\mathrm{L}\left(g_{H}<g_{L}\right)$. We will derive the condition under which this inequality will hold and consider what happens if it does not hold.

LEMMA 8 ( $i$ ) For $\lambda \geq \eta$, it is always the case that $g_{H}<g_{L}$, and (ii) for $\lambda<\eta$, a sufficient condition for $g_{H}<g_{L}$ is $\frac{\rho_{H}-\rho_{L}}{\eta-\lambda}>\frac{C(0)-1}{C(0)+1}$, where $C(g)=\left(\frac{\rho_{H}-g}{\eta}+1\right)\left(\frac{\rho_{L}-g}{\lambda}+1\right)>1$. Also, it follows that in the special case analysed above where $p \equiv \lambda=\eta$, the sufficient condition always holds.

Proof Comparing condition $(\mathrm{G})$ for parties $\mathrm{L}$ and $\mathrm{H}$, the only difference lies in the uncertainty-adjusted discount rate, $\rho_{i}+\Gamma_{i}(g)$. Thus, if $\rho_{H}+\Gamma_{H}(g)>\rho_{L}+\Gamma_{L}(g)$, the MB curve for party $\mathrm{H}$ lies entirely below the MB curve for party $\mathrm{L}$ for $g \in\left(0, \rho_{L}\right)$ (see Figure 3), so that $g_{H}<g_{L}$.

(i) It is easy to show that:

$$
\rho_{H}+\Gamma_{H}(g)-\rho_{L}-\Gamma_{L}(g)=\frac{\left(\rho_{H}-\rho_{L}\right)[C(g)+1]+(\lambda-\eta)[C(g)-1]}{C(g)}
$$

which is always positive for $\lambda \geq \eta$.

(ii) For $\lambda<\eta,(36)$ is positive iff $\frac{\rho_{H}-\rho_{L}}{\eta-\lambda}>\frac{C(0)-1}{C(0)+1}$. Moreover, $\frac{C(g)-1}{C(g)+1}$ is strictly decreasing in $g$, i.e. the maximum value is at $g=0$. Thus, $\frac{\rho_{H}-\rho_{L}}{\eta-\lambda}>\frac{C(0)-1}{C(0)+1}$ implies $\rho_{H}+\Gamma_{H}(g)>\rho_{L}+\Gamma_{L}(g)$.

Our results will hold if the parameter restrictions set out in Lemma 8 hold. But supposing that they don't, and party H adopts more growth-promoting policies than party L, i.e. $g_{H}>g_{L}$ ? In this case we will have a 'political reversal', in which

\footnotetext{
${ }^{25}$ One can think for instance of how long it took the UK's Labour Party in the 1980s to reassess its views on taxation and public spending and ask whether the Conservative Party's position on public spending was close to that of the median voter, or merely closer than that of the Labour opposition.
} 
consumers with a lower (higher) $\rho$ will vote for party H (L), and party L will be elected whenever the distribution function of voters is given by $F_{h}(\rho)$, whilst party $\mathrm{H}$ will be elected when the distribution function is $F_{l}(\rho)$. Apart from this, equilibrium condition (G) remains the same, except that in $\left(G^{\prime}\right) \lambda$ and $\eta$ will be interchanged.

Essentially, if the party preferences and other model parameters are such that there is a 'political reversal', the party which is more growth-oriented (L) will actually adopt a less growth-oriented strategy than party $\mathrm{H}$, due to the different degrees of political uncertainty faced by the two parties, i.e. due to L's lower prospects of being re-elected compared to H. As long as both party's have an equal probability of being in office (i.e. $p \equiv \lambda=\eta$ ), political reversals cannot occur as the two party's relative political preferences will dominate their relative policy stance. Thus, to summarise, all our results on policy myopia and the effect of policy uncertainty on fiscal policy still hold, even in this special case, but with a further twist regarding the two political parties' relative policy stance.

\section{Conclusions.}

This paper has argued that there is a significant link between increased political instability, reduced public investment and lower productivity growth in the OECD economies. Using political data and a panel for various countries over the period 196098 we show that there is a strong correlation between increased political instability and the reduction in government investment as a proportion of total fiscal spending.

We explain this observed correlation using a model of endogenous growth with rational partisan policymakers. Our model shows that, with greater political uncertainty, it is rational for policy myopia effects to set in and for incumbent politicians to reduce 
public spending and taxation, and to increase the share of government consumption in total government spending. These effects remain, even if there is a prospect of a exit from office and a subsequent return to power by the incumbent politician. From the point of view of economic efficiency, a more significant result is that political parties will adopt policy platforms with lower taxes and government investment spending than their own constituency. Furthermore, the outcome will generally be inefficient from the point of view of the median voter.

A number of extensions of this framework are possible and we intend to take these up in future work. The first potential objection to our observed correlations is that lower growth generates greater political instability. The impact of economic outcomes and fiscal policy decisions on the popularity and survival of governments has been recently analysed in Alesina et al. (1998), and we intend to perform some more formal empirical work to jointly model the probability of survival of governments and their fiscal decisions.

The second potential extension to our work is on the theoretical front. Our model tends to ignore the role of government debt in 'passing the buck' to future governments. The strategic role of government debt in this context has already been analysed by previous authors (e.g. Milesi-Ferretti and Spolaore, 1994). Whilst it is undoubtedly true that incumbents could use debt to constrain the choice of their successors, introducing such effects into our model would create considerable analytical complexities without producing any new results in this area. A more fruitful extension would be to allow political party platforms to gravitate gradually over time, following shifts in public opinion. For instance in a model with overlapping generations, one can conceive of outcomes in which demographic shifts may cause movements in the median voter's preferences over time. At the same time, political party platforms and 
polarisation will only evolve slowly because of the presence of interest groups (see

Alesina and Rosenthal, 1995). In these circumstances one might then be able to explain

changes in political polarisation and political platforms as functions of more

fundamental forces such as gradual demographic change in the industrialised economies.

\section{References}

Alesina, A. and Perotti, R. (1997). 'Fiscal adjustments in OECD countries: composition and macroeconomic effects.' IMF Staff Papers, 44 (2), 210-48.

Alesina, A. and Perotti, R. (1996). 'Reducing budget deficits.' Swedish Economic Policy Review, 3(1), 113-34.

Alesina, A. and Rosenthal, H. (1995). Partisan Politics, Divided Government, and the Economy.

Alesina, A. and Tabellini, G. (1990). 'A positive theory of fiscal deficits and government debt.' Review of Economic Studies, 57, 403-14.

Alesina, A., Perotti, R. and Tavares, J. (1998). 'The political economy of fiscal adjustments.' Brookings Papers on Economic Activity, 1, 197-266

Alesina, A., Ozler, S., Roubini, N. and Swagel, P. (1996). Journal of Economic Growth, 1, 189-211.

Aschauer, D. (1989). 'Is public expenditure productive?' Journal of Monetary Economics, 23, 177-200.

Barro, R. (1990). 'Government spending in a simple model of endogenous growth.' Journal of Political Economy, 98(5), S103-25.

Barro, R. (1996). 'Democracy and growth.' Journal of Economic Growth, 1, 1-27.

Benhabib, J. and Rustichini, A. (1996). 'Social conflict and growth.' Journal of Economic Growth, 1, 125-39.

Calvo, G. and Drazen, A. (1997). 'Uncertain duration of reform: dynamic implications.' NBER Working Paper 5925.

Dalle Nogare, C. (1997) 'Ideological Polarisation, Coalition Governments and Delays in

Stabilisation' University of Glasgow Discussion Paper n.9710.

Devarajan, S., Swaroop, V. and Zou, H. (1996). 'The composition of public expenditure and economic growth.' Journal of Monetary Economics, 37, 31344.

Devereux, M. and Wen, J.F. (1996). 'Political uncertainty, capital taxation and growth.' Mimeo, University of British Columbia.

Easterly, W. and Rebelo, S. (1993). 'Fiscal policy and economic growth: an empirical investigation.' Journal of Monetary Economics, 32, 417-58. 
Giavazzi, F. and Pagano, M. (1990). 'Can severe fiscal contractions be expansionary? Tales of two small European countries.' NBER Macroeconomics Annual, 75116. Giavazzi, F. and Pagano, M. (1995). 'Non-Keynesian effects of fiscal policy changes: international evidence and the Swedish experience.', NBER Working Paper n.5332.

Grilli, V., Masciandaro, D. and Tabellini, G. (1991). 'Political and monetary institutions and public financial policies in the industrial countries.' Economic Policy, 6, 341-92.

Holtz-Eakin, D. and Schwartz, A.E. (1994). 'Infrastructure in a structural model of economic growth.' NBER Working Paper n.4824.

Laakso and Taagepera (1979). 'Effective Number of Parties: A Measure with Application to Western Europe', Comparative Political Studies 12.

Mackie, D. and Rose, R. (1997). 'A Decade of Election Results: Updating the International Almanac' Studies in Public Policy, Centre for Study of Public Policy, University of Strathclyde.

Mackie, D. and Rose. R. (1991). 'The International Almanac of Electoral History' Third Edition, Macmillan, Hants.

Milesi-Ferretti, G.M. and Spolaore, E. (1994). 'How cynical can an incumbent be? Strategic policy in a model of government spending.' Journal of Public Economics, 55, 121-40.

Morrison, C. and Schwartz, A.E. (1992). 'State infrastructure and productive performance.' NBER Working Paper n.3981.

Munnell, A. (1990). 'Why has productivity growth declined? Productivity and public investment.' New England Economic Review, Jan/Feb, 3-22.

Murphy, K., Shleifer, A. and Vishny, R.W. (1991). 'The allocation of talent: implications for growth.' Quarterly Journal of Economics, 106, 506-30.

Muscatelli, V.A. (1998). 'Political consensus, uncertain preferences and central bank independence.', Oxford Economic Papers, 50, 412-30.

Perotti, R. (1993). 'Political equilibrium, income distribution and growth.' Review of Economic Studies, 60, 755-76.

Perotti, R. (1996). 'Growth, income distribution and democracy: what the data say.' Journal of Economic Growth, 1, 149-88.

Persson, T. and Tabellini, G. (1990). Macroeconomic policy, credibility and politics, Harwood Academic Publishers, London.

Persson, T. and Tabellini, G. (1998). 'Political Economics and Macroeconomic Policy.' forthcoming in J.Taylor and M. Woodford (eds.), Handbook of Macroeconomics, Amsterdam: North-Holland.

Rodrik, D. (1991). 'Policy uncertainty and private investment in developing countries.' Journal of Development Economics, 36, 227-49.

Rogoff, K. (1990). 'Equilibrium political budget cycles.' American Economic Review, 80, 21-36. 
Roubini, N. and Sachs, J. (1989a). 'Political and economic determinants of budget deficits in the industrialised countries.' European Economic Review, 33, 903-33.

Roubini, N. and Sachs, J. (1989b). 'Government spending and budget deficits in the industrialised countries.' Economic Policy, 8, 99-132.

Saint-Paul, G. and Verdier, T. (1993). 'Education, democracy and growth.' Journal of Development Economics, 42, 399-407.

Svensson, J. (1993). 'Investment, property rights and political instability: theory and evidence.' European Economic Review, forthcoming.

Tornell, A. and Velasco, A. (1992). 'The tragedy of the commons and economic growth: why does capital flow from poor to rich countries?' Journal of Political Economy, 100, 1208-31.

Woldendorp, J., Keman, H. and Budge, I. (1993). 'Political data 1945-90: Party government in 20 democracies.' European Journal of Political Research, 24 (1), 1-120. 
Table 2:

\begin{tabular}{|l|l|l|l|l|}
\hline & $1960-69$ & $1970-79$ & $1980-89$ & $1990-97$ \\
\hline intercept & $25.88(15.75)$ & $25.14(9.44)$ & $19.09(6.51)$ & $17.58(5.35)$ \\
DCPG & $-3.61(-2.41)$ & $-3.08(-2.00)$ & $-1.64(-1.00)$ & $-3.03(-1.28)$ \\
$\mathrm{R}^{2}$ & 0.308 & 0.236 & 0.071 & 0.109 \\
\hline intercept & $10.96(1.52)$ & $4.73(0.49)$ & $-0.49(-0.04)$ & $4.82(12.44)$ \\
GSE & $0.20(1.79)$ & $0.28(1.69)$ & $0.29(1.26)$ & $0.17(0.78)$ \\
$\mathrm{R}^{2}$ & 0.188 & 0.180 & 0.109 & 0.055 \\
\hline intercept & $20.80(2.28)$ & $13.41(1.16)$ & $19.97(1.7)$ & $12.39(0.93)$ \\
TERM & $0.03(0.25)$ & $0.09(0.65)$ & $-0.05(-0.34)$ & $0.02(0.14)$ \\
$\mathrm{R}^{2}$ & 0.004 & 0.032 & 0.088 & 0.002 \\
\hline intercept & $27.12(10.25)$ & $25.25(5.49)$ & $13.39(3.82)$ & $6.52(1.44)$ \\
$\mathrm{NTY}$ & $-2.06(-1.75)$ & $-1.90(-1.04)$ & $1.19(0.88)$ & $5.11(1.91)$ \\
$\mathrm{R}^{2}$ & 0.191 & 0.076 & 0.056 & 0.212 \\
\hline
\end{tabular}

